\title{
Behavior of Surrounding Soil during Construction and Its Countermeasures Using Pipe Jacking Method in Deep Strata
}

\author{
Takashi Senda, Hideki Shimada, Takashi Sasaoka, Kikuo Matsui \\ Department of Earth Resources Engineering, Kyushu University, Fukuoka, Japan \\ Email: m-sen@obayashi-road.co.jp
}

Received February 4, 2013; revised March 8, 2013; accepted April 8, 2013

Copyright (C) 2013 Takashi Senda et al. This is an open access article distributed under the Creative Commons Attribution License, which permits unrestricted use, distribution, and reproduction in any medium, provided the original work is properly cited.

\begin{abstract}
In Japan when urban infrastructures need to be constructed, the difficulty of utilizing the ground or shallow strata will lead to a more frequent use of the deep strata. The common construction methods are open-cut, pipe jacking, and shield methods. In recent years, a new pipe jacking method has been established that can be adapted to $20 \mathrm{~m}$ below the ground or more. Using this method, the drivage machine and the jacking pipe continue to move an underground until the completion of the driving. Therefore an over-cutting area (so-called tail-void) must be formed to lower the friction between the ground and the pipe. The tail-void is filled with lubrications. However, because the stress release from the ground continues to advance when the tail-void is formed, hence there are some challenges required to cope with the stability of the surrounding ground. In order to utilize the pipe jacking method in the deeper strata layers, the theory, analysis and installation of tail-void have to be systemized, and such systematic data must be stored. Therefore, the conditions of tail-void in the deep pipe jacking method are discussed using numerical analyses.
\end{abstract}

Keywords: Pipe Jacking System; Deep Strata; Tail-Void

\section{Introduction}

In Japan, the land of large metropolitan areas is highly utilized in increasingly complex conditions; therefore, the underground area is used to establish social infrastructures because of difficulties to use on the ground. Even in the publicly used shallow strata such as road sections, social infrastructures including subways, water and sewage systems, electrical equipment, communications facilities, and gas pipelines have already been installed and are very congested. Nowadays, when urban infrastructures need to be further constructed, the difficulty of using the ground or shallow strata will lead to the more frequent use of the deep strata.

The general advantages of using the deep strata which will help maintain the quality of social capital include stability, earthquake resistance, constant temperature and humidity, and blockages of vibration and noise, all of which will not affect the view on the ground. A good quality of social infrastructure can be installed by taking advantages of the deep strata construction. Consequently, the development of an effectively, appropriately designed deep strata will be strongly encouraged.
Generally used construction methods include open-cut, pipe jacking, and shield methods. In the past, even during construction of the shallow strata, open-cut methods were widely used because construction had to be precise, reliable, and economically efficient. However, due to the neighboring construction it is difficult to secure road traffic, prevent construction hazards such as vibration and noise, and to also take steps to protect the existing congested underground installations. On the other hand, the pipe jacking method has been widely adopted as a general construction method owing to its recent marvelous technological development [1].

Nowadays, in order to grasp the ground constructions after using the shield method, the movement of the ground is frequently predicted by numerical analysis. Many cases are recognized as plain strain and axisymmetric problems in the sectional and vertical directions in the shield construction. In this paper, various factors that may influence the deformation of the surrounding ground are simulated and analyzed. These factors include the balancing between the pressure of cutting face and the earth pressure, the cutting condition of the face, ground deformation by excavation, the friction between the surround- 
ing surface of drivage machine and its contact ground, generation of tail-void, and lubricant. Those analysis were considered using the finite element method, which produce great results for the prediction of deformation behavior of the ground during the shield construction. From this point of view, this method was adopted for analyzing the pipe jacking method [2].

\section{What is the Pipe Jacking}

In the pipe jacking method, drivage machine is set at the head of the pipeline and the pipes are jacked forward with the hydraulic jack, located at the starting shaft.

The pipe jacking, like many other methods of below ground construction, is best employed in stable, water free soil conditions. Unfortunately, with the demands on available space and the need to provide more services, it is not always possible to select stable strata, which means that contractors have to contend with difficult ground below the water table $[3,4]$. The slurry pipe jacking system is applicable to the above situations.

Figure 1 shows the pipe jacking system scheme. This system can be used to construct pipe tunnels up to 3000 $\mathrm{mm}$ in diameter and construct both long (maximum length: $1000 \mathrm{~m}$ ) and curved tunnels (minimum curvature radius: $25 \mathrm{~m})$.

Recent technological developments have led to successful methods for stabilizing unstable strata by excluding water from excavations by means of tail-void with mud slurry. This system meets modern environmental standards. This type of mud slurry is formed by water, decomposed granite soil, carboxyl methyl cellulose, lost circulation control material, bentonite, fine aggregate, and other materials. Figure 2 shows an illustration of the pipe and the soil in this system. The proportional mixes vary the viscosity and the seepage capacity of the mud slurry and will be determined by whether mud slurry is required to strengthen the soil.

This system is used as follows:

1) Install the pushing equipment in the starting pit, and then set the drivage machine.

2) Extend the rear-end pushing jack and push the dri- vage machine.

3) By repetition of the pushing process, if the rear-end driving after one concrete pipe length $(2.5 \mathrm{~m})$ is driving in, connect another pipe.

4) After driving is completed, recover the drivage machine from the arrival pit.

More widely used techniques that are now being used elsewhere for micro-tunneling, use remote control drivage methods in conjunction with pipe jacking. During the pushing processes, the mud slurry is injected into the face and tail-void, which is between the pipe and the soil. After tail-void is filled by the slurry, soil is stabilized due to the slurry pressure. To minimize ground deformation in the pushing process, it is necessary to maintain the slurry pressure that was kept on the underground water pressure at plus $20 \mathrm{kPa}$ [5].

Thus, tail-void plays an important role in reducing the friction resistance in pushing the pipes and maintaining earth covering pressure.

\section{Numerical Analysis}

The boundary conditions of the ground, where the pipe jacking construction is made, are so complex and wideranging that in many cases 3-dimentional effect cannot be ignored when considering the design of the pipe jacking construction. Therefore, excavation elements were used to create a 3-dimentional finite element method considering the actual construction process of pipe jacking construction.

\subsection{Outline of Analysis}

In the pipe jacking construction, just after the drivage machine passes by the tail, the tail-void is generated due to the difference of the outer diameter of each pipe, which releases stress in the ground. As the actual construction lubricant is injected into the tail-void to prevent the ground from deformation due to stress release caused by formation of the tail-void in the ground. To simulate this situation in the analysis, a nodal force equivalent to the injection pressure is applied to the soil element where

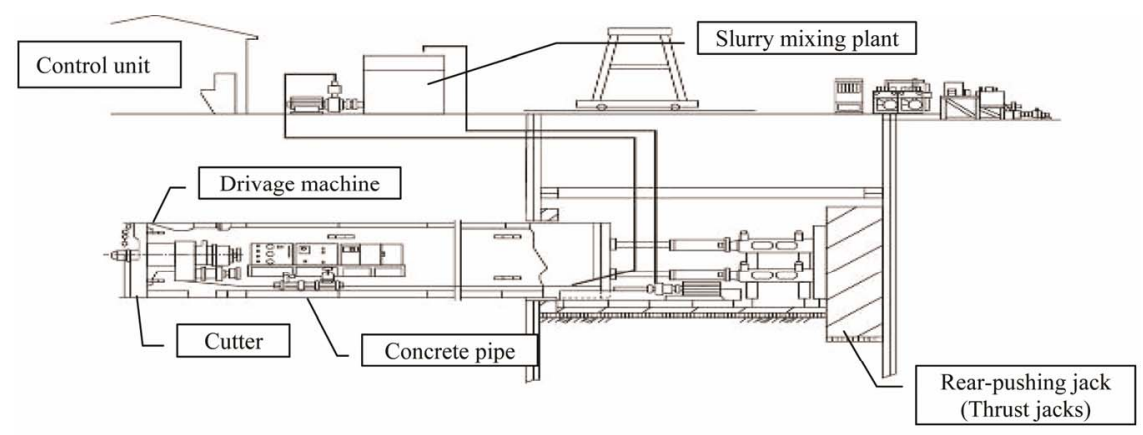

Figure 1. Pipe jacking scheme. 
the stress is released after the tail of the drivage machine passes by.

\subsection{Input Parameters}

Tables 1 and $\mathbf{2}$ show the input parameters used in the analysis. The appropriate pressure of the cutting face must be applied against the earth covering.

The material values of the lubricant were the ones that are illustrated graphically with the logarithmic functional approximation value of Young's modulus and Poisson's ratio according to the result of the uniaxial compression test as shown in Figure 3.

Figure 4 shows analysis model. A half section model with a length of $40 \mathrm{~m}$ and a width of $150 \mathrm{~m}$ was used as the analysis range because both loading and structural systems were symmetrical.

\section{Results and Discussion}

Figure 5 shows the deformations of the crown at the tailvoid during pipe jacking of 10, 20 and $30 \mathrm{~m}$. The pressure of the cutting face was acted against the front face of

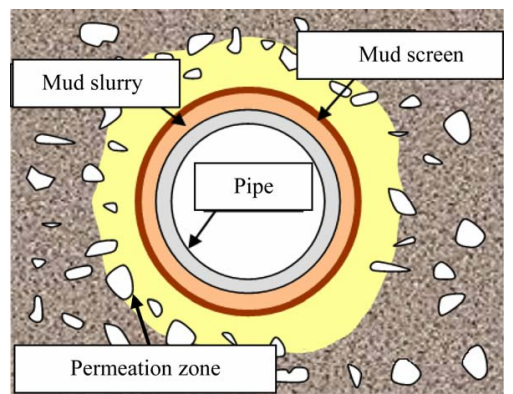

Figure 2. Illustration of a concrete pipe and soil.

Table 1. Properties of soils, pipe and lubricant.

\begin{tabular}{|c|c|c|c|c|c|c|}
\hline & \multirow[b]{2}{*}{ Mud-stone } & \multirow[b]{2}{*}{ Clay } & \multirow[b]{2}{*}{ Sand } & \multirow[b]{2}{*}{ Pipe } & \multicolumn{2}{|c|}{ Lubricant } \\
\hline & & & & & $\begin{array}{c}\text { After } \\
\text { injection }\end{array}$ & $\begin{array}{c}1 \text { month } \\
\text { passed }\end{array}$ \\
\hline $\begin{array}{l}\text { Young's } \\
\text { modulus: E } \\
(\mathrm{MPa})\end{array}$ & 74 & 50 & 55 & $2.2 \times 10^{3}$ & $9.8 \times 10^{-4}$ & 0.43 \\
\hline $\begin{array}{l}\text { Poisson's } \\
\text { ratio: } v\end{array}$ & 0.30 & 0.33 & 0.35 & 0.20 & 0.45 & 0.39 \\
\hline $\begin{array}{l}\text { Density } \\
\left(\mathrm{MN} / \mathrm{m}^{3}\right)\end{array}$ & 0.021 & 0.024 & 0.021 & 0.080 & 0.021 & 0.021 \\
\hline
\end{tabular}

Table 2. Cutting face pressure.

\begin{tabular}{cc}
\hline Earth covering: $\mathrm{H}$ & Cutting face pressure (MPa) \\
\hline $20 \mathrm{~m}$ & 0.44 \\
$40 \mathrm{~m}$ & 0.86 \\
$60 \mathrm{~m}$ & 1.28 \\
\hline
\end{tabular}

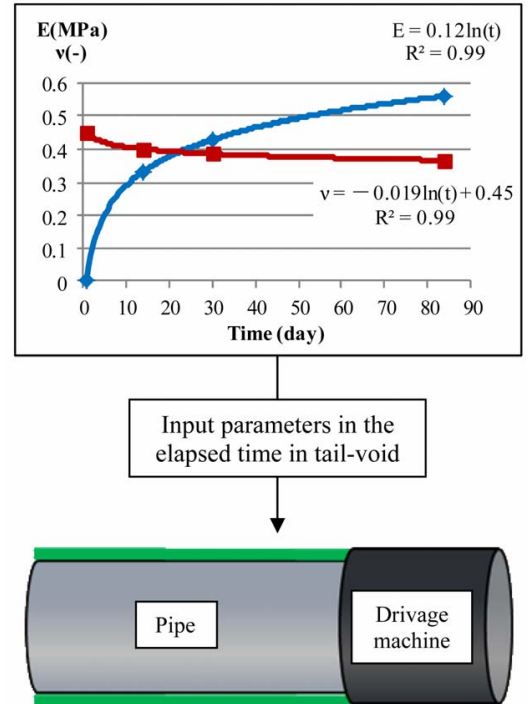

Figure 3. Young's modulus and Poisson's ratio elapsed time after injection.
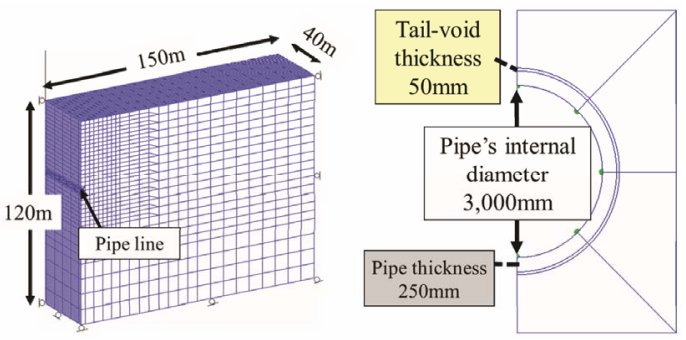

Figure 4. Analysis model.

excavation, causing upheaval before settlement starts. After the drivage machine passes by, settlement is generated from 30 to $35 \mathrm{~mm}$. Constructing tail-void cause large deformation. Therefore, this phenomenon should be taken care in pipe jacking.

Figure 6 shows the deformations of the crown at the tail-void when pipe jacking has reached a $30 \mathrm{~m}$ point of excavation at the various earth coverings of 20,40 , and $60 \mathrm{~m}$. As the earth covering increases, the deformation amount of tail-void also increases. At the earth covering of $40 \mathrm{~m}$, settlement has reached a maximum of about 34 $\mathrm{mm}$.

Figure 7 shows the deformation amount dependency to the soil properties. A tendency was found that the larger the cohesion is, the smaller the deformation amount. In particular, the deformation amount of sandy soil and cohesive soil reached $50 \mathrm{~mm}$ or more, which is generally a value that cannot secure an effective area of tail-void.

The analytical results this time show that even under the conditions of easy-to-collapse soil and high water pressure, if mud screen is able to retain the area of surrounding pipes with enough pressure to cope with the earth pressure and hydraulic pressure, then it can decrease fric- 
tional forces on pipelines. This is very effective in construction.

Based on the analytical results shown in Figure 5, Figure 8 shows that the range, affected by the amount of surface settlement of the ground surface and the top layer at the center of drivage machine, became smaller, if the earth covering became larger. It was $3.4 \mathrm{~mm}$ at an earth covering of $60 \mathrm{~m}$. It is presumed that the range affected by the ground subsidence in the horizontal direction should be on a straight line of about 42 degree.

\section{Conclusion}

Based on the analytical results, it was found that if the earth covering in the deeper ground increases, the surrounding soil during the pipe jacking construction, and

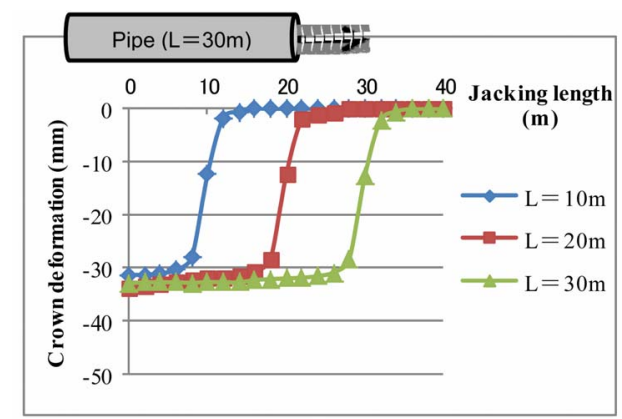

Figure 5. Effect on the deformation by differences of thrust length: $L(m)$.

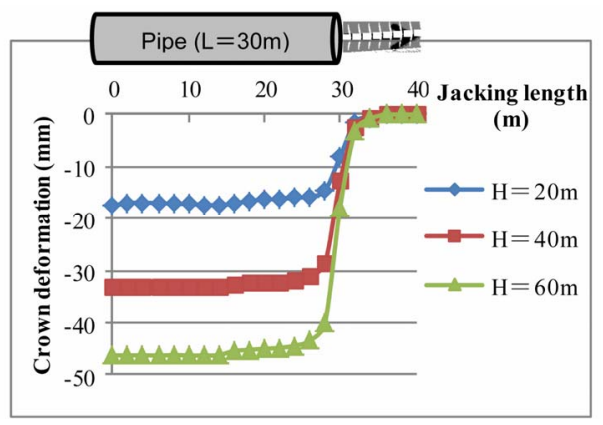

Figure 6. Effect on the deformation by differences of earth covering: $\mathbf{H}(\mathrm{m})$.

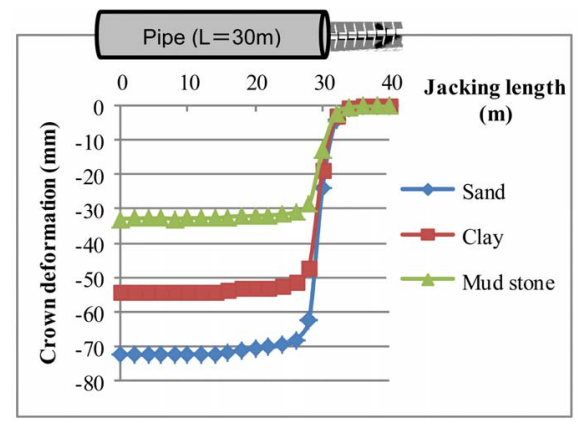

Figure 7. Effect on the deformation by differences of soils.

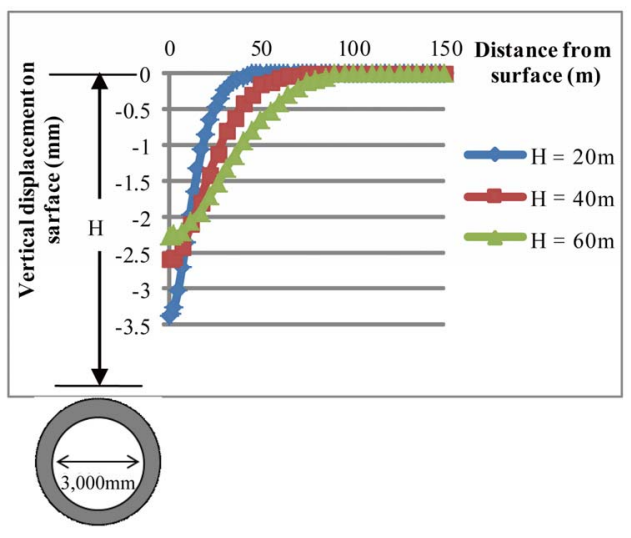

Figure 8. Relationship between the vertical displacement on the surface and the distance from the center.

the tail-void in particular, must be looked at, due to the increased deformation.

Now that long distance and narrow curve jacking techniques have been established and watertight joints for installation have been rapidly developed, the pipe jacking method can be applied to the pipe installation in underground deeper than $20 \mathrm{~m}$ of earth covering. However, the stress release of the ground continues along with the formation of tail-void. Therefore, there are many challenges to cope with for the improvement of stability in the surrounding ground.

While the drivage machine approaches and passes by, the stress and strain conditions change with time. Plural factors, such as changing position of drivage machine and surrounding friction, can often affect the ground simultaneously. In addition, a long-term ground subsidence followed by the ground deformation at the time of construction can be caused directly by the soil disturbance resulting from the ground deformation during construction. Therefore most of the ground deformations caused by the pipe jacking construction may be caused by changing stress and strain conditions over the course of construction.

That is why the discussion of appropriate lubricants and injection methods, etc. in preparation for such changes is inevitable.

\section{REFERENCES}

[1] Japan Tunneling Association, "Trend of Using Deep Underground and Activity Report," 1997.

[2] H. Akagi and K. Komiya, "Ground Behavioral Analysis in Consideration of the Construction Process of Shield Tunneling in Finite Element Method," Journal of Japan Society of Civil Engineers, Vol. III-25, No. 481, 1993, pp. 59- 68.

[3] J. M. Cole, "Pipe Jacking Case Histories, Tunnels and Tunneling," 1977.

[4] C. M. Hough, "Pipe Jacking Case Histories, Tunnels and 
Tunneling," 1978.

[5] S. Katano and T. Ogawa, "Effect of Slurry Shield Tunneling in Soft Alluvial Clay on an Adjacent Underground Subway Structure," Proceedings of International Con- gress on Tunneling and Ground Conditions, Cairo, April 1994, pp. 151-156. 